\title{
Study the effect of some parameters on the extracted ion beam from cold cathode Penning ion source
}

\author{
A.G. Helal, H. El-Khabeary and S.I. Radwan \\ Accelerators \& Ion Sources Department, Basic Nuclear Science Division, Nuclear \\ Research Center, Atomic Energy Authority, P.N.13759, Cairo, Egypt
}

\begin{abstract}
A cold cathode Penning ion source was designed and operated at the optimum conditions. Its characteristics were determined using nitrogen and argon gases at pressure equal to $9 \times 10^{-4} \mathrm{mmHg}$. Efficiency of this ion source was determined using nitrogen and argon gases. Also, ion source aspect ratio was determined using argon gas. The effect of negative voltage applied on Faraday cup using argon gas was studied. Finally, a simple retarding electrostatic field energy analyzer has been designed to determine the ion energy distribution.
\end{abstract}

Keywords: PIG ion source, Retarding field energy analyzer, aspect ratio, efficiency, ion energy distribution.

\section{INTRODUCTION}

Ion Sources are machines that produce a stream of ion beams that can be used in the fields of particle accelerator physics, ion implantation, mass separator, controlled fusion research and for producing and/or tailoring the properties of a thin solid film [1-7]. They can be categorized according to their physical properties, operational parameters and applications [810]. Direct current (DC) gas discharge is self maintained by applying D.C field between the anode and cathode that immersed inside the discharge vessel in the presence of a gas at low pressures [11-14]. According to the current which carry, the gas discharge can be classified into Townsend discharge carrying currents up to $10^{-6} \mathrm{~A}$, the glow discharge carrying currents from $10^{-6} \mathrm{~A}$ to $10^{-1} \mathrm{~A}$ and arc discharge of currents more than $10^{-1} \mathrm{~A}$.

The Penning ion source is a low gas pressure that cold cathode type uses crossed electric and magnetic fields $[4,15,16]$. In which primary electrons are released from the cathode either by ion impact (cold cathode PIG) or by thermionic emission (hot cathode PIG). The cold cathode PIG ion source is found to be more successful for many applications as accelerators, sputtering and evaporation of surfaces, electromagnetic separation of isotopes and fusion applications [17-19].

The ion energy is an important plasma parameter that influences the ablation of surfaces, etching and the deposition processes [20]. Electrostatic probes as the retarding potential analyzers or ion traps depending on the electric charge of ions and electrons for both energy filtering and particle detection. Several experimental and theoretical methods have been developed and applied to determine the ion flux and the ion energy distribution (IED) at the substrate such as the use of ion mass/energy analyzers [21-25]. A Retarding Potential 
Military Technical College

Kobry Elkobbah,

Cairo, Egypt

April 19-21,2016

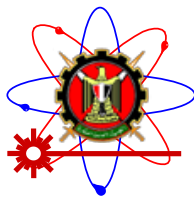

$8^{\text {th }}$ International Conference on Mathematics and Engineering Physics (ICMEP-8)

Analyzer (RPA), retarding field or gridded energy analyzer, was used to determine the ion energy distribution [26]. Several RPA designs have been proposed to diagnose cold and dense plasmas $[27,28]$. The retarding potentials have been used in a variety of analyzers and applications as in aboard spacecraft and satellites, chemical physics, plasmas, electron cloud diagnostics and ion beams [29-32].

The aim of this work is to determine IED for cold cathode Penning ion source as a function of the operating pressure and the bias voltage of the metal plate, called a reflector (retarding grid) using simple RFEA. Also, the ion source efficiency and aspect ratio were determined. Finally, study the effect of applying negative voltage of Faraday cup on the extracted ion beam.

\section{EXPERIMENTAL SETUP}

The dimensions of cold cathode Penning ion source at the optimum operation conditions are shown in figure (1). It consists of copper cylindrical anode of $60 \mathrm{~mm}$ length, $50 \mathrm{~mm}$ diameter and two molybdenum cathodes. The anode has cylindrical hollow canal of $40 \mathrm{~mm}$ length, $12 \mathrm{~mm}$ inner diameter and has two cones of $15 \mathrm{~mm}$ length, $22 \mathrm{~mm}$ upper diameter and $12 \mathrm{~mm}$ bottom diameter at the two sides of canal anode. The two movable cathodes are fixed in Perspex insulator of $50 \mathrm{~mm}$ outer diameter, $22 \mathrm{~mm}$ inner diameter and $38 \mathrm{~mm}$ length and placed symmetrically at two ends of the anode. Each cathode have $14 \mathrm{~mm}$ diameter and 25 mm length. The anode - cathode distance, $\mathrm{d}_{\mathrm{A}-\mathrm{C}}$, was fixed at the optimum distance equal to 6 $\mathrm{mm}$. The copper emission electrode of $20 \mathrm{~mm}$ diameter with $2 \mathrm{~mm}$ thickness. It has central aperture diameter, $\mathrm{D}_{\mathrm{em}}$. fixed at the optimum diameter equal to $2.5 \mathrm{~mm}$ and placed at the middle of the anode to extract ion beam. Its inner surface towards plasma formation is isolated from the anode by Perspex insulator except an area of $5 \mathrm{~mm}$ optimum diameter, $\mathrm{A}_{\mathrm{em}}$, to confine the discharge in this area. Faraday cup, collector, is placed at optimum distance from the emission disc aperture, $d_{\text {em.-F.c. }}$ equal to $3 \mathrm{~cm}$ and used to collect the output ion beam. The axial Samarium Cobalt, SmCo, permanent magnet of intensity, B, was fixed at the optimum intensity equal to 300 Gauss that gives the maximum ion beam current [33].

Fig. (1) A cold cathode Penning ion

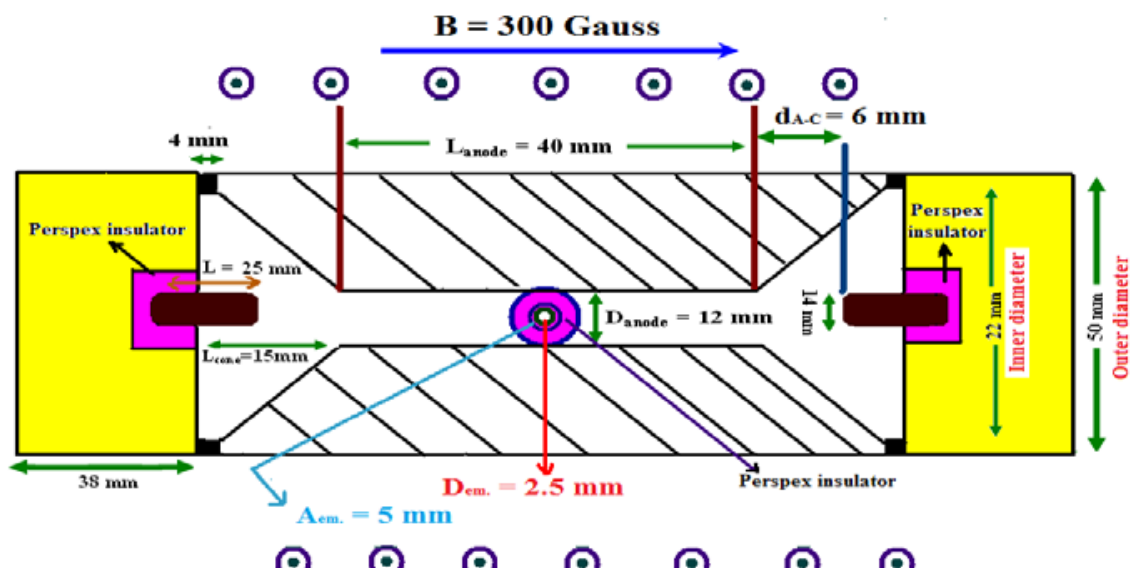

source with optimum dimensions [33]. 
Military Technical College

Kobry Elkobbah,

Cairo, Egypt

April 19-21,2016

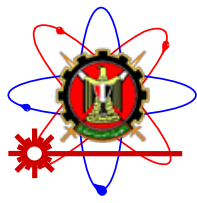

$8^{\text {th }}$ International Conference on

Mathematics and Engineering

Physics (ICMEP-8)

A schematic diagram of this Penning ion source with simple RFEA is shown in figure (2). This analyzer consists of two grids, retarding and screen grids, placed between emission electrode and Faraday cup. The analyzer dimensions are the emission electrode - retarding grid distance, retarding grid - screen grid distance and screen grid - Faraday cup distance equal to $1 \mathrm{~cm}$. The inner holes diameter of retarding and screen grids is equal to $2 \mathrm{~mm}$. Figure (3) shows the electrical circuit of ion source RFEA.

Fig. (2) A schematic diagram of this Penning ion

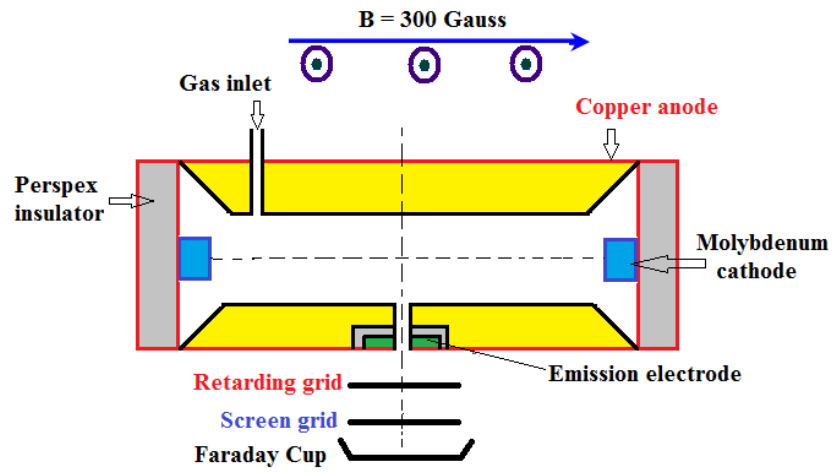

$\odot \odot \odot$
Fig.(3): Electrical circuit of this

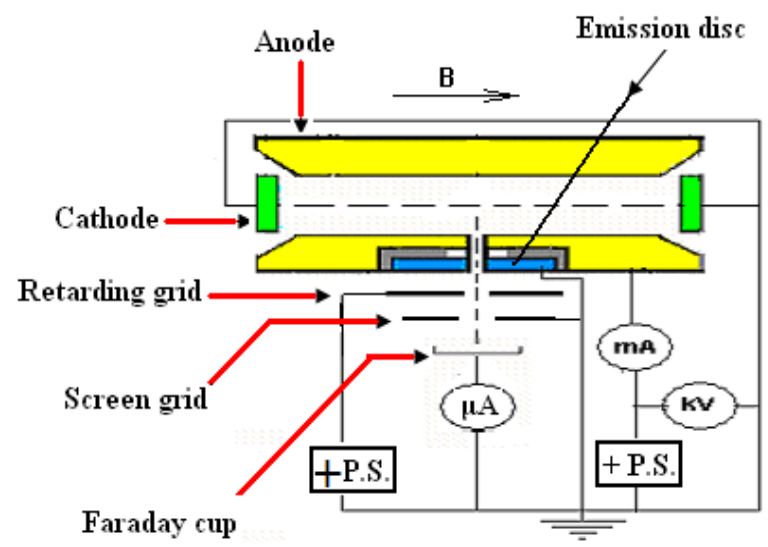

source with RFEA.

source with RFEA.

This ion source is placed in vacuum system that evacuated by rotary pump to get a pressure in the range of $\left(10^{-2}-10^{-3}\right) \mathrm{mmHg}$ and stainless steel mercury diffusion pump of speed $270 \mathrm{~L} / \mathrm{s}$ to yield a low pressure in the range of $\left(10^{-4}-10^{-6}\right) \mathrm{mmHg}$. Nitrogen and argon gases was admitted into the ion source through a finely controlled needle valve.

\section{Principal operation of retarding field energy analyzer (RFEA)}

More sophisticated analyzers can be used for the analysis of the atoms, molecules or their ions as well as the electrons in plasma. RFEA is essentially a group of electrically isolated grids and an ion collector where all positioned along the ion beam path. In which, the external bias voltages are typically applied to the substrate to manipulate the ion energy distribution during processing [34]. There are different types of RFEA [35]. Traditional RFEA with two parallel plates was developed in the past in which the first plate is grounded and the second one is biased to a negative high voltage to retard the electron beams [36]. Only those particles whose longitudinal kinetic energy is higher than the retarding potential can pass from the second electrode and reach the collector forming a current signal, where other electrons will be reflected. This structure has good resolution only for a beam with trajectories parallel to the axis of this analyzer. Ions above a certain energy threshold, set by a voltage of a set of retarding grids, are detected by a collector producing a current.

In this experiment, IED was investigated by using a simple RFEA shown in figure (3). This energy analyzer consists of two copper grids which were of $40 \%$ transmission. The two grids are screen and retarding grids, see figure (4). The positive potential, $\mathrm{V}_{\text {ret, }}$ was applied to the retarding grid and the screen grid was at the earth potential as the emission electrode. The particles are subject to a swept retarding potential on retarding grid which ranges from zero to large positive values where the ions are the sampled quantity. The screen grid is appropriately earth biased to reject the electrons, with Faraday cup usually held at a potential such that the secondary electrons from Faraday cup are not accelerated towards the retarding grid and no 


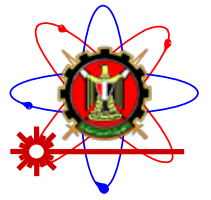

contribution to the total collected current. Which it screens Faraday cup from the high field produced by the retarding grid.

Fig.(4) Pathways of plasma electrons through RFEA.

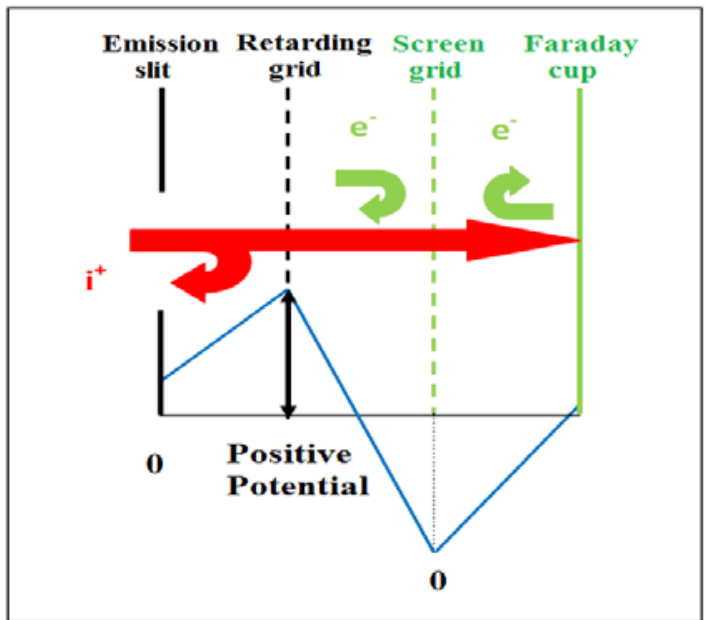

ions and

The relationship between the collected current and ion retarding potential for a RPA is given by [37]:

$\mathrm{I}(\mathrm{V})=\left(\mathrm{e}^{2} \mathrm{n}_{\mathrm{i}} \mathrm{A}_{\text {probe }} / \mathrm{m}_{\mathrm{i}}\right) / \int_{V}^{\mathrm{se}} f\left(V^{v}\right) d V^{t}$

Where $\mathrm{V}$ is the voltage of ion retarding grid, $\mathrm{f}$ is the ion energy distribution function and $A_{\text {probe }}$ is the area of the ion current collector. By differentiating this equation, it is easily shown that:

$-\frac{d I}{d V}=\frac{\theta^{2} n_{i} A_{\text {grobs }}}{m_{\mathrm{i}}} f(V)$

From equation (2), the ion energy distribution, $\mathrm{f}(\mathrm{V})$ can be calculated.

\section{RESULTS AND DISCUSSIONS}

This ion source dimensions have been done at the optimum parameters to improve its efficiency which are suitable for different applications. The experimental results were measured at different pressures using argon and nitrogen gases.

\section{1- Optimum output characteristics using nitrogen and argon gases}

Figure (5) shows the output ion beam current, $I_{b}(\mu \mathrm{A})$, versus discharge current, $I_{d}(m A)$, at optimum parameters, $\mathrm{d}_{\mathrm{A}-\mathrm{C}}, \mathrm{D}_{\text {em. }}, \mathrm{A}_{\text {em. }}, \mathrm{d}_{\mathrm{em} .-\mathrm{F} . \mathrm{C}}, \mathrm{d}_{\mathrm{mag}-\mathrm{A}}$ and $\mathrm{B}$ equal to $6 \mathrm{~mm}, 2.5 \mathrm{~mm}, 5 \mathrm{~mm}, 3 \mathrm{~cm}, 1.5$ $\mathrm{cm}$ and 600 Gauss respectively and pressure, $\mathrm{P}$, equal to $9 \times 10^{-4} \mathrm{mmHg}$ using nitrogen and argon gases. It is clear that the output ion beam current increases with increasing the discharge current reaching a maximum output ion beam current of argon and nitrogen equal to $280 \mu \mathrm{A}$ and $144 \mu \mathrm{A}$ respectively. 


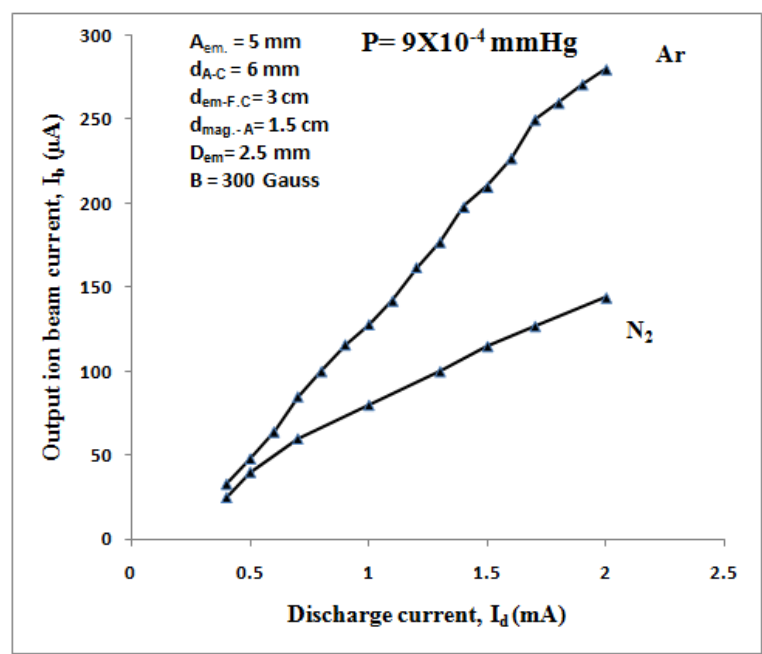

Fig.(5) Output ion beam current versus discharge current at optimum parameters and $P=9 \times 10^{-4}$ mmHg using nitrogen and argon gases.

\section{2 - Ion source efficiency}

The efficiency of ion source can be determined by the ratio of the output ion beam current to the discharge current. Figure (6) shows the relation between the air pressure, P, versus the ion source efficiency at discharge voltage, $\mathrm{V}_{\mathrm{d}}$, equal to $3.9 \mathrm{KV}$ using nitrogen and argon gases. It is clear that the ion source efficiency at P equal to $5 \times 10^{-4} \mathrm{mmHg}$ reaching $43 \%$ and $22 \%$ for argon and nitrogen gases respectively due to the higher atomic mass of argon gas.

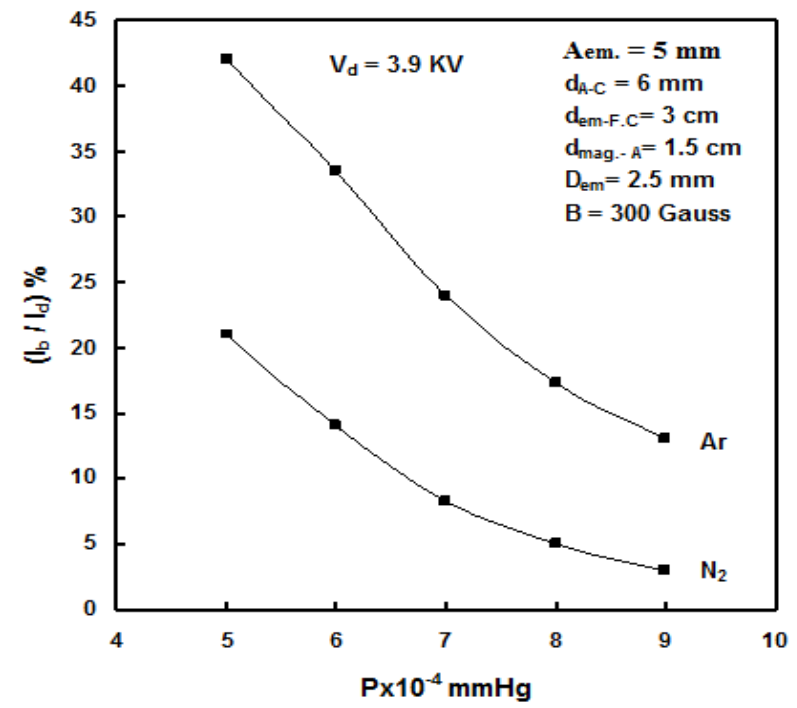

Fig.(6) Gas pressure versus ion source efficiency at optimum parameters and $V_{d}=3.9 \mathrm{KV}$ using nitrogen and argon gases. 
Military Technical College

Kobry Elkobbah,

Cairo, Egypt

April 19-21,2016

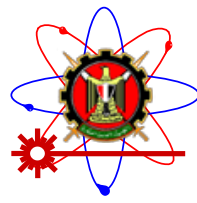

$8^{\text {th }}$ International Conference on

Mathematics and Engineering

Physics (ICMEP-8)

\section{3- Determination of ion source aspect ratio}

The experimental results of different anode - cathode distances which obtained before [44]. The aspect ratio has been determined using the discharge current and output ion beam current which obtained before. Figure (7) shows the relation between output ion beam current and aspect ratio at constant pressure equal to $9 \times 10^{-4} \mathrm{mmHg}$ and discharge current equal to 1 $\mathrm{mA}$ using argon gas. It is clear that the maximum value of the output ion beam current is obtained at aspect ratio equal to 0.21 reaching $125 \mu \mathrm{A}$ argon gas. This indicates that the optimum anode-cathode distance equal to $6 \mathrm{~mm}$.

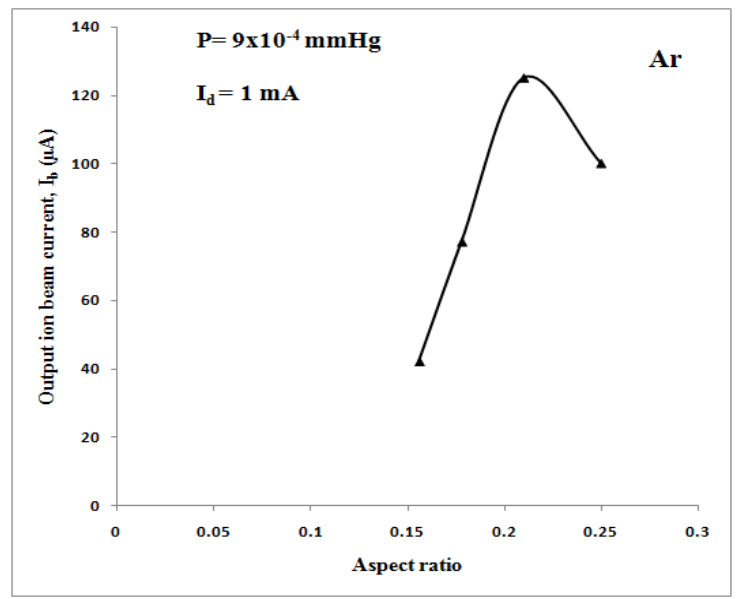

Fig. (7) Output ion beam current versus aspect ratio at $P=9 \times 10^{-4} \mathrm{mmHg}$ and $I_{d}=1 \mathrm{~mA}$ using argon gas.

\section{4- Effect of negative voltage applied on Faraday cup}

Figure (8) shows the output ion beam current, $I_{b}(\mu A)$, versus discharge current, $I_{d}(m A)$, at optimum parameters for different negative voltages, $V_{n g}$, applied on Faraday cup and $\mathrm{P}=$ $9 \times 10^{-4} \mathrm{mmHg}$ using argon gas. It is clear that $\mathrm{I}_{\mathrm{b}}$ decreases by applying negative voltage on Faraday cup. This is due to the high energy of secondary electrons produced from Faraday cup which allows to make neutralization with the ion beam reaching Faraday cup. By applying more negative voltage, the output ion beam current is decreased.

Figure (9) shows the output ion beam current, $I_{b}(\mu A)$, versus the negative voltage, $V_{n g}$, applied on Faraday cup at different $I_{d}$ using argon gas. It is clear that the higher ion beam current is at higher discharge current value. There are two minimum points $\left(\mathrm{V}_{\text {ng }}\right.$ equal to 500 , $1500 \mathrm{~V}$ ) at which the ion beam current decreased before and after them increased. There is a maximum point, $\mathrm{V}_{\mathrm{ng}}$ equal to $1000 \mathrm{~V}$, at which the output ion beam current increased reaching $280 \mu \mathrm{A}$ for $\mathrm{I}_{\mathrm{d}}$ equal to $2 \mathrm{~mA}$. But at $\mathrm{I}_{\mathrm{d}}$ equal to $0.4 \mathrm{~mA}$, the output ion beam current and negative voltage relation is nearly linear. But as the value of discharge current increased, the maximum value at $\mathrm{V}_{\mathrm{ng}}$ equal to $1000 \mathrm{~V}$ is increased. This is due to the plasma intensity is increased, the output ion beam current increased by applying negative voltage applied on Faraday cup. 


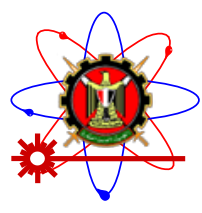

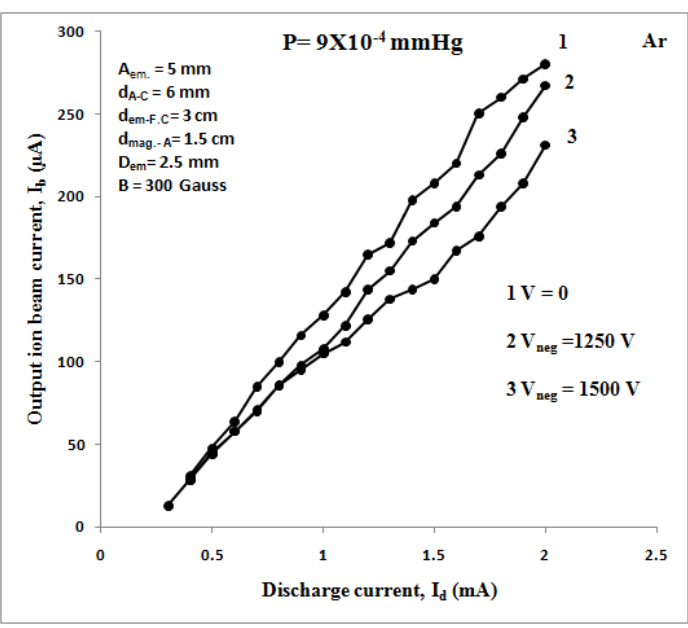

Fig.(8) Output ion beam current versus discharge current at optimum parameters and different negative optimum voltages applied on Faraday cup using argon gas.

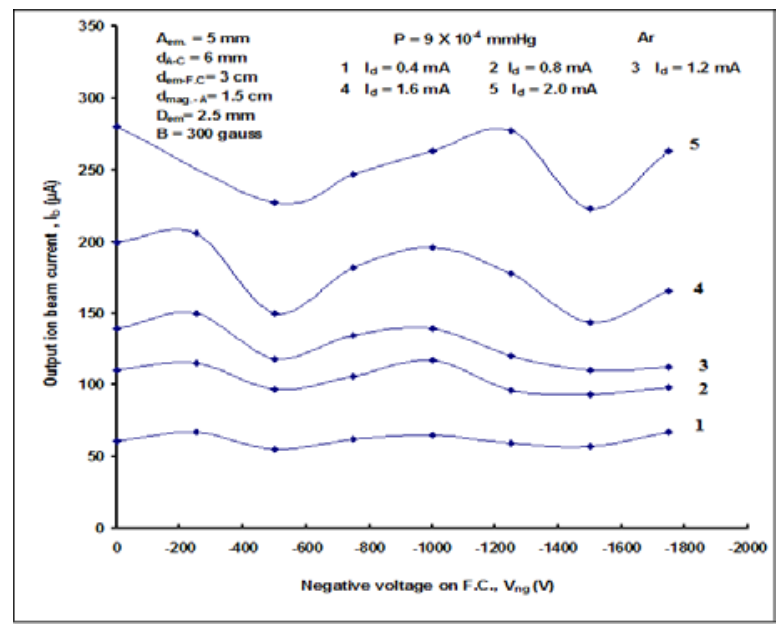

Fig.(9) Output ion beam current versus negative voltages applied on Faraday cup at optimum parameters and different discharge current using argon gas.

\section{5- Effect of retarding field energy analyzer on extracted ion beam}

Here, the retarding grid is connected to positive potential, while the emission electrode and screen grid are connected to the earth potential.

\section{1- Ion retarding}

The output for IED measurement is shown in fig. (10) that shows the relation between the voltage applied to retarding grid, $\mathrm{V}_{\text {ret }}(\mathrm{V})$, versus the output ion beam current at ion source optimum parameters, $\mathrm{P}$ equal to $9 \times 10^{-4} \mathrm{~mm} \mathrm{Hg}$, and discharge voltage equal to 2 and $3 \mathrm{KV}$ using argon gas. It is clear that the output ion beam current is higher at $\mathrm{V}_{\mathrm{d}}$ equal to $3 \mathrm{KV}$. At $\mathrm{V}_{\mathrm{d}}$ equal to $2 \mathrm{KV}$, the output ion beam current is decreased about $25 \%$ its value $3 \mathrm{KV}$. It is concluded that the output ion beam current decreases when the applied $\mathrm{V}_{\text {ret }}<\mathrm{V}_{\mathrm{d}}$ and saturated at $V_{\text {ret }} \geq V_{d}$. By other words at $V_{d}$ equal to $2 \mathrm{KV}$, the retarding grid repels all ions with energies of less than $2 \mathrm{KV}$ and more than that can pass. That means it make filter of the ion energies. Figure (11) shows the photographic picture indicates the effect of argon ion beam on copper Faraday cup at optimum parameters in case of positive potential applied on the retarding grid.

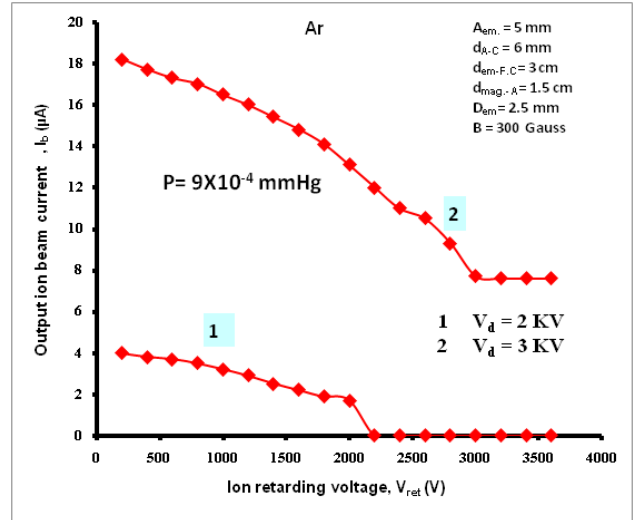

Fig.(10) Output ion beam current versus positive potential applied on retarding grid at optimum parameters and $\mathrm{P}=9 \times 10^{-4} \mathrm{mmHg}$ using discharge voltages 2 and $3 \mathrm{KV}$ of argon gas.

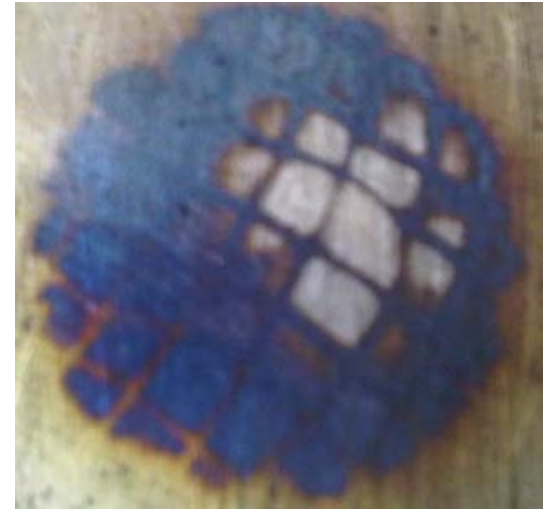

Fig.(11) Photographic picture of copper Faraday cup at optimum parameters for applying positive potential on retarding grid using argon gas. 


\section{2- Ion energy distribution}

Figure (12) shows the IED for this ion source at P equal to $9 \times 10^{-4} \mathrm{mmHg}$ and $\mathrm{V}_{\mathrm{d}}$ equal to 2 and $3 \mathrm{KV}$ using argon gas. It is clear that ion energy distribution has the same behavior for different discharge voltages. The ions emitting from plasma boundary and moving towards the ion exit aperture, accelerated in the field between the plasma boundary and the emission electrode. When they become fast and collide with the gas atoms, the collision can result in an ion extracting an electron from gas atom, resulting in it becoming a fast neutral atom while the slow atom becomes a slow positive ion. This process does not change the number of the ions in the system, is called charge transfer process with general form:

\section{$\mathrm{X}^{+}$(Energetic ion) $+\mathrm{X}$ (Slow atom) $\rightarrow \mathrm{X}^{+}$(Slow ion) $+\mathrm{X}$ (Fast atom)}

For each value of direct current, dc, bias applied on retarding grid, the ion energy distribution has two peaks. The broader peaks at higher energy correspond to ions bombarding the substrate and an upward shift of the plasma potential by an amount equal to this applied dc bias. The sharper peaks at lower energy correspond to ions bombarding the substrate during the afterglow. The mean energy of these peaks corresponds to the applied dc bias.

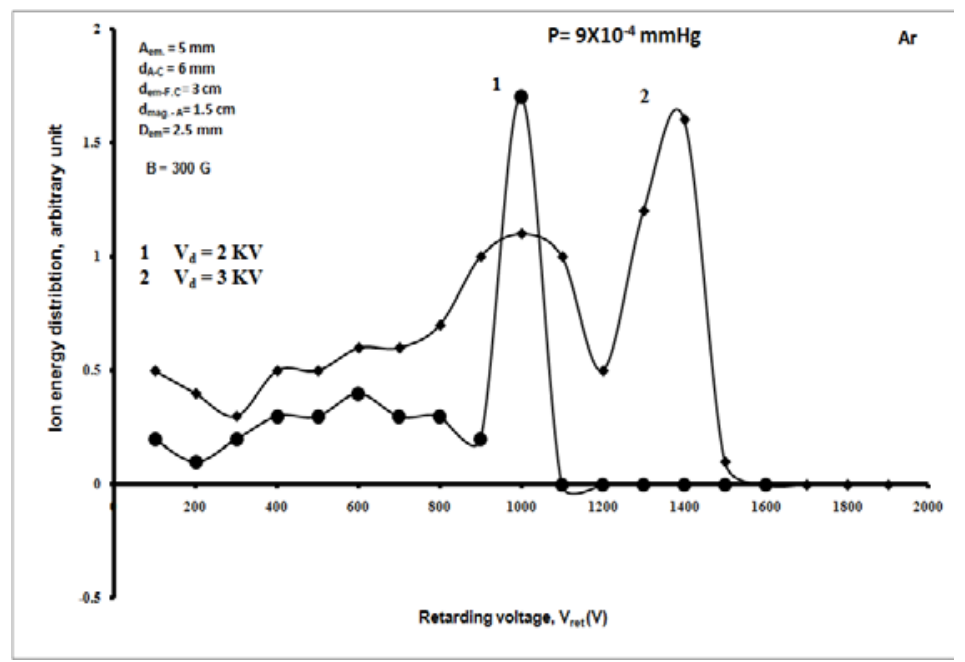

Fig.(12) Ion energy distribution at the optimum parameters, $P=9 \times 10^{-4} \mathrm{mmHg}$ and different discharge voltage using argon gas.

\section{Conclusions}

In this study, the output ion beam characteristic was done at a pressure equal to $9 \times 10^{-4}$ mmHg where a maximum ion beam current for argon gas is higher than that for nitrogen gas due to heavier argon mass than that of nitrogen which allows more electron collisions. Also, it is found that the ion source efficiency is equal to $43 \%$ and $22 \%$ for argon and nitrogen gases respectively. The ion source aspect ratio is determined that indicates the maximum output ion beam current at the optimum anode-cathode distance. From the study of the negative voltage applied on Faraday cup, it is concluded that output ion beam current decreases due to the energy of secondary electrons produced from Faraday cup is increased and allows to make neutralization with the ion beam pathway to Faraday cup. 
Military Technical College

Kobry Elkobbah,

Cairo, Egypt

April 19-21,2016

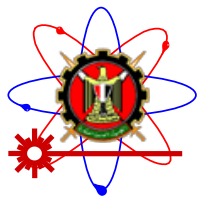

$8^{\text {th }}$ International Conference on

Mathematics and Engineering

Physics (ICMEP-8)

Finally, we can determine IED using electrostatic analyzer as RFEA. When the ion retarding grid has a potential less than the discharge voltage, no ions can be reached Faraday cup. While this grid has a potential more than the discharge voltage, the ions can pass through and reach Faraday cup.

\section{REFERENCES}

[1] N. Angert; Ion Sources, Proc. CERN Fifth General Accelerator Physics Course, Jvyaskla, September, CERN 94-01, 619 (1994).

[2] L. Valyi; Atom and Ion Sources, John Wiley \& Sons, New York (1977)

[3] M. M. Abdelrahman; Ain Shams Engineering Journal, 3, 71 (2012).

[4] I. G. Brown; The Physics and Technology of Ion Sources, 2nd, Revised and Extended Edition, J.Wiley \& Sons, New York (2004).

[5] J. J. Cuomo, S. M. Rossnagel, H. Kaufman; Handbook of Ion Beam Processing Technology, Noyes Publ., Park Ridge (1989).

[6] E. Oks; "Plasma cathode electron sources, physics, technology, applications", Weinheim, Germany: Wiley VCH Verlag GmbH \& Co. KGaA (2006).

[7] L. Valyi; Atoms and Ion Sources, John-Wiley, Hungary (1977).

[8] A. M. Abdelraheem, M. M. Abdelrahman, H. El-Khabeary; Journal of Asian Scientific Research 4, 230 (2014).

[9] M. M. Abdelrahman, F. W. Abdelsalam; Nuclear Instr. and Methods Physics Research B 269, 1761 (2011).

[10] G. Christoph; Lecture series "Ion sources \& Diagnostics". ASTeC (south): Rutherford Appleton Laboratory RAL, Accelerator Science \& Technology Centre (2011).

[11] K. Cinar, M.Sc. Thesis, Physics Department, Middle East Techanical University, Turkish (2011).

[12] J. Menart, J. Shang, R. Kimmel, and J. Hayes; $34^{\text {th }}$ AIAA plasma dynamics and lasers conference, 4165 (2003).

[13] J. Menart, S. Handerson, C. Atzbach, J. Shang, R. Kimmel, and J. Hayes; $34^{\text {th }}$ AIAA plasma dynamics and lasers conference, 2262 (2004).

[14] R. L. Kimmel, J. R. Hayes, J. A. Menart, and J. Shang; $34^{\text {th }}$ AIAA plasma dynamics and lasers conference, 509 (2004).

[15] J.L. Rovey; Plasma Sources Sci. Technol. 17, 3 (2008).

[16] J.L. Rovey, B.P. Ruzic, T.J. Houlahan; Rev. Sci. Instrum. 78, 10, (2007).

[17] D. L. Hillis, P. D. Morgan, J. K. M. Groth, M. F. Stamp, M. Hellermann, Von. Ehrenberg, V. Kumar; Rev. Sci. Instrum. 70, 359 (1999).

[18] D. L. Hillis, C. C. Klepper, M. Hellermann, Von J. Ehrenberg, K. H. Finken, G. Mank; Fusion Eng. Des. 347, 34 (1997). 
Military Technical College

Kobry Elkobbah,

Cairo, Egypt

April 19-21,2016

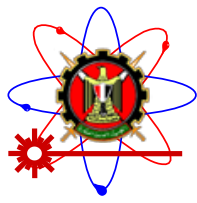

$8^{\text {th }}$ International Conference on

Mathematics and Engineering

Physics (ICMEP-8)

[19] Peisach and Alfassi; Elemental Analysis by Particle Accelerators, CRC press, London (1992).

[20] K. Denieffe, C. M. O. Mahony, P. D. Maguire, D. Gahan, and M. B. Hopkins; J. Phys. D, Appl. Phys., 447 (2011).

(21) J. Janes and C. Huth; J. Vac. Sci. Technol. A 10, 3086 (1992).

(22) I .C. Abraham, J.R. Woodworth, M.E. Riley, P.A. Miller, T. W. Hamilton and B. P. Aragon; J. Vac. Sci. Technol. 20, 1759 (2002).

(23) J. R. Woodworth, I. C. Abraham, M.E. Riley, P. A. Miller, T. W. Hamilton, B. P. Aragon, R. J. Shul and C.G. Willison; J. Vac. Sci. Technol. A 20, 873, 86 (2002).

(24) M. Kratzer, R. P. Brinkmann, W. Sabisch and H. Schmidt; J. Appl. Phys. 90, 2169 (2001).

(25) A. Agarwal and M. J. Kushner; J. Vac. Sci. Technol. A 23, 1440 (2005).

[26] H. Boersch; Zeitschrift Phys., 139, 2, 115 (1954).

[27] C. M. Marrese, N. Majumdar, J. Haas, G. Williams, L. B. King, and A. D. Gallimore; Proc. $25^{\text {th }}$ Int. Elect. Propuls. Conf., Cleveland, OH, USA, 397 (1997).

[28] J. M. Partridge; "Development and implementation of diagnostics for unsteady small-scale plasma plumes”, Ph.D. dissertation, Dept. Mech. Eng., Worcester Polytech. Inst., Worcester, MA, USA (2008).

[29] R. A. Pitts, R. Chavan, S. J. Davies, S. K. Erents, G. Kaveney, G. F. Matthews, G. Neill, J. E. Vince; Rev. Sci. Instrum. 74, 4644 (2003).

[30] R. J. Macek, A. Browman, M. Borden, D. Fitzgerald, T. S. Wang, T. Zaugg, K. Harkay, and R. Rosenberg; Proceedings of the 2003 Particle Accelerator Conference Portland (IEEE, New York), (2003).

[31] R. A. Rosenberg and K. C. Harkay; Nucl. Instrum. Methods Phys. Res., A 453, 507 (2000).

[32] H. C. Paulini and U. Littmark; Nucl. Instrum. Methods Phys. Res. B 58, 260 (1991).

[33] Adel Gomah Helal, Hesham El-Khabeary Tawfik and Samah Ibrahim Radwan; Journal of Physical Science and Application 3, 4, 229 (2013).

(34) M.M. Patterson, H-Y. Chu and A .E. Wendt; Plasma Sources Sci. Technol. 16, 257 (2007).

[35] J. A. Simpson; Rev. Sci. Instrum. 32, 1283 (1961).

[36] Yun Zou, " Experimental studies on resistive-wall instability and development of beam diagnostics for the university of Maryland electron ring facility", Ph.D. thesis, University of Maryland (2000).

[37] L. B. King and A. D. Gallimore; Rev. Sci. Instrum. 68, 2, 1183 (1997). 